\title{
EFEKTIFITAS TEKNIK GAMBAR PERINGATAN BAHAYA MEROKOK DAN PENDIDIKAN NORMA SUBJEKTIF DENGAN INTENSI BERHENTI MEROKOK
}

\section{Effectiveness Of Picture Warning Techniques Of Smoking Hazards And Subjective Normal Education With Intention Of Stop Smoking}

\author{
Hamdani $^{1}$, Herdianti ${ }^{2}$ \\ ${ }^{1}$ Program Studi Kesehatan Masyarakat, STIKES Harapan Ibu, Jambi \\ ( hamdanimpd3@gmail.com ) \\ ${ }^{2}$ Program Studi Kesehatan Lingkungan, STIKES Ibnu Sina, Batam \\ ( herdiantinyup@gmail.com )
}

\begin{abstract}
ABSTRAK
Organisasi Kesehatan Dunia (WHO) menyatakan, tembakau membunuh lebih dari 5 juta orang per tahun, dan diproyeksikan akan membunuh 10 juta sampai tahun 2020. Intensi berhenti merokok dipengaruhi oleh norma subyektif dan gambar peringatan bahaya merokok. Untuk Provinsi Jambi jumlah perokok adalah sebanyak 22,9\%. Adapun tujuan penelitian ini adalah untuk mengetahui pengaruh gambar peringatan bahaya merokok dan norma subyektif dengan intensi berhenti merokok mahasiswa STITEKNAS Jambi. Penelitian ini merupakan penelitian kuantitatif dengan desain Cross Sectional. Populasi adalah seluruh mahasiswa Stiteknas Kota Jambi yang merokok berjumlah 226 orang. Sampel diambil dengan teknik Accidental Sampling berjumlah 76 orang. Hasil penelitian diketahui intensi berhenti merokok kurang baik 40 (52,6\%), gambar peringatan bahaya merokok kurang baik $37(48,7 \%)$ dan norma subjektif kurang baik $34(44,7 \%)$. Terdapat pengaruh antara gambar peringatan bahaya merokok dengan intensi berhenti merokok $(\mathrm{r}=0,361 \mathrm{p}$ value $=0,032)$. Tidak terdapat pengaruh antara norma subjektif dengan intensi berhenti merokok $(r=0,278 \mathrm{p}$ value $=$ 0,117). Berdasarkan hasil penelitian dan pembahasan dapat disimpulkan bahwa ada pengaruh gambar peringatan bahaya merokok dengan intensi berhenti merokok dan tidak ada pengaruh norma subyektif dengan intensi berhenti merokok mahasiswa STITEKNAS Jambi.

Kata Kunci : Intensi Berhenti Merokok, Gambar Peringatan Bahaya Merokok, Norma subjektif
\end{abstract}

\section{ABSTRACT}

The World Health Organization (WHO) says tobacco kills more than 5 million people per year, and is projected to kill 10 million by 2020. The intention of quitting smoking is influenced by subjective norms and images of warnings of smoking. For Jambi Province the number of smokers is 22.9\%. The purpose of this study is to determine the effect of smoking warning pictures and subjective norms with the intention to quit smoking STITEKNAS Jambi students. This research is a quantitative research with Cross Sectional design. The population is all students of Stiteknas Kota Jambi who smoke amounted to 226 people. Samples were taken with Accidental Sampling technique amounted to 76 people. The result of the research showed that the intention to quit smoking was not good 40 (52,6\%), picture of dangerous smoking warning 37 (48,7\%) and subjective norm was not good 34 (44,7\%). There is influence between smoking warning picture with smoking quit intention $(r=0,361 p$ value $=0,032)$. There is no influence between subjective norm and intention to stop smoking $(r=0,278 p$ value $=$ 0,117). Based on the results of research and discussion can be concluded that there is the effect of 
smoking warning images with the intention to stop smoking and no influence of subjective norms with the intention to quit smoking STITEKNAS Jambi students.

Key words: Stop Smoking Intentions, Warning Pictures Smoking Dangers, Subjective Norms.

\section{PENDAHULUAN}

Merokok merupakan salah satu kebiasaan yang lazim ditemui dalam kehidupan sehari-hari. Merokok merupakan bagian hidup masyarakat. Dari segi kesehatan tidak ada satu titik yang menyetujui atau melihat manfaat yang dikandungnya. Organisasi Kesehatan Dunia (WHO) menyatakan, tembakau membunuh lebih dari 5 juta orang per tahun, dan diproyeksikan akan membunuh 10 juta sampai tahun $2020^{1}$.

Secara global, rokok membunuh hampir 6 juta orang per tahun, termasuk sekitar 600.000 kematian akibat asap rokok. Jika kecenderungan ini terus berlanjut, diperkirakan bahwa rokok akan menyebabkan sekitar 8 juta kematian per tahun pada tahun 2030. Pada tahun 2015, diproyeksikan bahwa 33\% dari semua kematian terkait tembakau di seluruh dunia $^{2}$.

Perilaku merokok di Indonesia masih belum terjadi penurunan dari tahun 2007 ke 2013, bahkan cenderung meningkat dari 34,2 persen tahun 2007 menjadi 36,3 persen tahun 2013. Sedangkan rerata jumlah batang rokok yang dihisap adalah sekitar 12,3 batang. Untuk Provinsi Jambi adalah 22,9\%. Perokok setiap hari terbanyak di Kota Jambi. Rerata batang rokok yang dihisap perhari per orang di provinsi Jambi adalah 14,4 batang (setara satu bungkus). Jumlah rerata batang rokok terbanyak yang dihisap ditemukan di kabupaten Kerinci (16 batang) dan di Batanghari (15-16 batang) .

Perokok pemula didominasi oleh remaja. Usia remaja adalah usia yang labil, banyak remaja yang mudah terpengaruh untuk merokok karena gencarnya iklan rokok di media dan juga oleh teman sebaya. Merokok pada saat usia remaja membuatnya sangat berisiko terkena masalah kesehatan yang serius karena masih berada pada usia pertumbuhan. Rokok tidak hanya menyebabkan masalah kesehatan pada tingkat fisik namun juga emosionalnya ${ }^{4}$.

Masyarakat berhak mendapatkan informasi dan peringatan yang jelas dan benar atas dampak yang ditimbulkan akibat merokok. Walaupun lebih dari 90\% masyarakat pernah membaca peringatan kesehatan berbentuk tulisan di bungkus rokok, hampir separuhnya tidak percaya dan $26 \%$ tidak termotivasi berhenti merokok. Studi di berbagai negara membuktikan peringatan tertulis yang disertai gambar lebih efektif dari pada hanya berbentuk tulisan saja. Oleh karena itu, pesan kesehatan pada kemasan rokok wajib dicantumkan dalam bentuk gambar dan tulisan 
untuk meningkatkan kesadaran perokok dan bukan perokok akan bahaya merokok bagi kesehatan ${ }^{5}$.

Peringatan bahaya merokok diharapkan memiliki dampak signifikan terhadap kesehatan publik dan menurunkan jumlah perokok, sehingga meningkatkan tingkat harapan hidup, dan status kesehatan yang lebih baik, dan gambar bahaya dari tembakau ditujukan kepada sebagian mahasiswa. Gambar juga mendorong mahasiswa untuk membuat mereka tidak merokok di kampus dan melihat manfaat berhenti merokok ${ }^{6.7}$.

Teori yang membahas mengenai niat adalah yang diperkenalkan oleh Ajzen dan Fishbein. Teori ini menerangkan bahwa intensi terbentuk atas tiga komponen yakni sikap, norma subjektif dan kontrol perilaku yang dimiliki setiap individu untuk melakukan suatu perilaku. Ketiga komponen tersebut berinteraksi dan berpengaruh terhadap intensi yang pada gilirannya akan menentukan akan dilakukannya atau tidak suatu tindakan ${ }^{8}$.

Hasil survei awal yang peneliti lakukan terhadap 243 mahasiwa STITEKNAS Jambi didapatkan bahwa hanya sebanyak 17 (7\%) responden yang tidak merokok, sedangkan 226 (93\%) responden sebagai perokok aktif.

Berdasarkan latar belakang diatas, maka penulis melakukan penelitian tentang pengaruh gambar peringatan bahaya merokok dan norma subyektif dengan intensi berhenti merokok mahasiswa STITEKNAS Jambi tahun 2015. Adapun tujuan penelitian ini adalah untuk mengetahui pengaruh gambar peringatan bahaya merokok dan norma subyektif dengan intensi berhenti merokok mahasiswa STITEKNAS Jambi tahun 2015

\section{METODE}

Penelitian ini merupakan penelitian kuantitatif dengan rancangan penelitian cross sectional. Penelitian ini dilaksanakan pada bulan November tahun 2015. Populasi adalah mahasiswa STITEKNAS Jambi yang merokok berjumlah 226 orang. Jumlah sampel sebanyak 76 diambil menggunakan tekhnik Accidental Sampling.

Variabel independen nya adalah gambar peringatan bahaya merokok dan norma subyektif, Sedangkan variabel dependen nya adalah intensi berhenti merokok. Kuesioner digunakan untuk mengambil data tentang pengaruh gambar peringatan bahaya merokok dan norma subyektif terhadap intensi berhenti merokok.

Analisis data yang digunakan adalah analisis Univariat untuk melihat gambaran masing-masing variabel, dan analisis Bivariat menggunakan uji korelatif lambda untuk melihat besar korelasi antara variabel independen dan dependen dengan derajat kemaknaan 0,05. Apabila p-value $\leq 0.05$ berarti terdapat hubungan yang bermakna, 
sedangkan $\mathrm{P}$-value $>0,05$ artinya tidak terdapat hubungan yang bermakna.

\section{HASIL DAN PEMBAHASAN}

1. Karakteristik Responden

Hasil penelitian menujukkan bahwa

dari 76 responden yang telah diteliti

didapatkan sebanyak 57 orang $(75,0 \%)$ umur

mulai merokok 10-20 tahun dan sebanyak 19

orang $(25,04 \%)$ umur mulai merokok $20-30$

tahun. Rata-rata mulai merokok pada umur 18 tahun. Sebanyak 41 orang $(53,9 \%)$ perokok

sedang dan sebanyak 35 orang $(46,1 \%)$

perokok sedang. Rata-rata jumlah batang

rokok/hari sebanyak 16 batang. Sebanyak

47orang $(61,8 \%)$ alasan coba-coba dan ebanyak 29 orang $(38,2 \%)$ alasan ikut-ikutan. (Tabel 1).

Tabel 1. Distribusi berdasarkan Karakteristik Responden Tahun 2015

\begin{tabular}{lcc}
\hline Variabel & $\begin{array}{c}\text { Frekuens } \\
\text { i }\end{array}$ & $\%$ \\
\hline Umur mulai merokok & 57 & 75,0 \\
10-20 tahun & 19 & 25,0 \\
20-30 tahun & & \\
Jumlah Batang Rokok Per & & 53,9 \\
Hari & 41 & 46,1 \\
Berat (>15 batang) & 35 & \\
Sedang (5-14 batang) & & 61,8 \\
Alasan Mulai Merokok & 47 & 38,2 \\
Coba-coba & 29 & \\
Ikut-ikutan & & \\
\hline
\end{tabular}

\section{Hasil Univariat}

Hasil penelitian menunjukkan bahwa sebanyak 40 orang $(52,6 \%)$ memiliki intensi berhenti merokok kurang baik dan sebanyak 36 orang $(47,4 \%)$ memiliki intensi berhenti merokok baik. Sebanyak 37 (48,7\%) gambar peringatan bahaya merokok kurang baik dan sebanyak $39 \quad(51,3 \%)$ gambar peringatan bahaya merokok baik. Sebanyak 34 orang $(44,7 \%)$ memiliki norma subyektif kurang baik dan sebanyak 42 orang $(55,3 \%)$ memiliki norma subyektif baik. (Tabel 2). 
Tabel 2. Distribusi Gambaran Intensi Berhenti Merokok, Gambar Peringatan Bahaya Merokok dan Norma Subyektif Pada Mahasiswa STITEKNAS Jambi Tahun 2015

\begin{tabular}{lcc}
\hline Variabel & Frekuensi & \% \\
\hline Intensi Berhenti Merokok & & 52,6 \\
Kurang Baik & 40 & 47,4 \\
Baik & 36 & \\
Gambar Peringatan & & 48,7 \\
Kurang baik & 37 & 51,3 \\
Baik & 39 & \\
Norma Subyektif & & 44,7 \\
Tidak Baik & 34 & 55,3 \\
Baik & 42 & \\
\hline
\end{tabular}

Berdasarkan hasil analisis tentang Gambaran Intensi Berhenti Merokok menujukkan bahwa responden yang memiliki intensi berhenti merokok kurang baik adalah sebanyak $40(52,6 \%)$. Hal ini karena Hasil penelitian menujukkan masih adanya responden yang memiliki intensi berhenti merokok yang kurang baik, antara lain karena sebagian besar responden menyatakan dalam waktu dekat tidak akan berhenti merokok dan responden tidak mengurangi jumlah rokok yang di hisap setiap hari.

3. Hasil Analisis Bivariat
Hasil penelitian diperoleh nilai $r=$ 0,361 yang menujukkan korelasi sedang. Sedangkan nilai $\mathrm{p}$ value $=0,032$ artinya korelasi bermakna menujukkan bahwa adanya korelasi yang bermakna antara gambar peringatan bahaya merokok dengan intensi berhenti merokok dan diperoleh nilai $r=0,278$ yang menujukkan korelasi sedang. Sedangkan nilai $\mathrm{p}$ value $=0,117$ artinya korelasi tidak bermakna. tidak adanya korelasi yang bermakna antara norma subyektif dengan intensi berhenti merokok. (Tabel 3).

Tabel 3. Distribusi Pengaruh Gambar Peringatan Bahaya Merokok Dan Norma Subyektif Dengan Intensi Berhenti Merokok Mahasiswa STITEKNAS Jambi tahun 2015

\begin{tabular}{|c|c|c|c|c|c|c|c|c|c|}
\hline \multirow{3}{*}{ Variabel } & & \multicolumn{4}{|c|}{ Intensi Berhenti Merokok } & \multirow{2}{*}{\multicolumn{2}{|c|}{ Jumlah }} & \multirow{3}{*}{$r$} & \multirow{3}{*}{$P$ value } \\
\hline & & \multicolumn{2}{|c|}{ Kurang Baik } & \multicolumn{2}{|c|}{ Baik } & & & & \\
\hline & & Jml & $\%$ & Jml & $\%$ & Jml & $\%$ & & \\
\hline \multirow{2}{*}{$\begin{array}{l}\text { Gambar } \\
\text { Peringatan }\end{array}$} & Kurang baik & 27 & 73,0 & 10 & 27,0 & 37 & 100 & \multirow{2}{*}{0,361} & \multirow{2}{*}{0,032} \\
\hline & Baik & 13 & 33,3 & 26 & 66,7 & 39 & 100 & & \\
\hline \multirow{2}{*}{$\begin{array}{l}\text { Norma } \\
\text { Subyektif }\end{array}$} & Kurang baik & 24 & 70,6 & 10 & 29,4 & 34 & 100 & \multirow{2}{*}{0,278} & \multirow{2}{*}{0,117} \\
\hline & Baik & 16 & 38,1 & 26 & 61,9 & 42 & 100 & & \\
\hline
\end{tabular}


Dari hasil uji statistik tentang pengaruh gambar peringatan bahaya merokok dengan intensi berhenti merokok menujukkan bahwa adanya korelasi yang bermakna. Hasil ini sejalan dengan penelitian Wahyuni (2006) menyatakan bahwa sikap terhadap label peringatan bahaya merokok memberi pengaruh 19,9\% dalam meningkatkan intensi berhenti merokok mahasiswa Fakultas Teknik Industri UAD Yogyakarta ${ }^{9}$. Gambar peringatan bahaya merokok dapat mempengaruhi niat seseorang untuk berhenti merokok, peringatan kesehatan pada paket tembakau (rokok) akan meningkatkan kesadaran perokok terhadap risiko merokok. Penggunaan gambar dengan penggambaran grafis penyakit dan gambar negatif lainnya memiliki dampak yang lebih besar daripada kata-kata saja, dan penting dalam mencapai sebagian besar orang di seluruh dunia yang tidak bisa membaca ${ }^{10}$.

Sedangkan hasil uji statistik tentang pengaruh norma subyektif dengan intensi berhenti merokok menunjukkan bahwa tidak adanya korelasi yang bermakna. Penelitian ini tidak sejalan dengan penelitian Permatasari (2012) bahwa norma subyektif mempengaruhi intensi berhenti merokok. seorang perokok akan mempertimbangkan bagaimana dukungan yang diberikan oleh orang tua, saudara maupun teman untuk berhenti merokok. Perokok akan berusaha untuk merubah perilaku merokok sehubungan dengan tekanan serta dorongan dari lingkungan sekitarnya, tekanan tersebut juga mempengaruhi niat perokok untuk melanjutkan atau berhenti merokok ${ }^{11}$.

Intensi ataupun niat seseorang untuk berhenti merokok sangat bergantung dari norma subyektif yang diterima, norma subyektif dapat diartikan sebagai dorongan anggota keluarga, termasuk kawan terdekat memepengaruhi agar seseorang dapat menerima perilaku tertentu yang kemudian diikuti dengan saran, nasehat dan motivasi dari keluarga atau kawan. Kemampuan anggota keluarga atau kawan terdekat mempengaruhi seorang individu untuk berperilaku seperti yang mereka harapkan diperoleh dari pengalaman, pengetahuan dan penilaian individu tersebut terhadap perilaku tertentu dan keyakinannya melihat keberhasiloan orang lain berperilaku seperti yang disarankan ${ }^{12}$.

Tidak adanya pengaruh antara norma subyektif dengan intensi berhenti merokok dikarenakan responden kurang mendapatkan dukungan dan anjuran dari teman dan dosen untuk tidak merokok. Hal ini dibuktikan dengan jawaban dari kuesioner yang dijawab oleh responden yang menujukkan bahwa teman responden tidak pernah memberi tahu tentang bahaya merokok, teman responden tidak pernah menganjurkan dan melarang untuk tidak merokok, dan dosen dikampus tidak menganjurkan agar tidak merokok. 


\section{KESIMPULAN DAN SARAN}

Berdasarkan hasil penelitian dan pembahasan dapat disimpulkan bahwa ada pengaruh gambar peringatan bahaya merokok Sebaiknya pengelola kampus STITEKNAS Jambi menjadikan daerah kampus sebagai Kawasan Tanpa Rokok (KTR) dengan menetapkan aturan yang mengatur hal

\section{DAFTAR PUSTAKA}

1. Bustan. 2007. Epidemiologi Penyakit Tidak Menular. Jakarta. Rineka Cipta.

2. Eriksen. 2014. Global Tobacco Use And Cancer: Findings And Solutions From The Tobacco Atlas. School Of Public Health. Georgia State University

3. Kemenkes RI. 2013. Riset Kesehatan Dasar Indonesia Tahun 2013. Jakarta

4. Padmaningrum. 2012. Rokok Mengandung Zat Adiktif Yang Berbahaya bagi kesehatan.

5. PP RI. 2012. Bahan Yang Mengandung Zat Adiktif Berupa Produk Tembakau Bagi Kesehatan. Jakarta

6. Sulivan, Michle G. 2011. Kemasan dimaksudkan untuk menghalangi merokok. Gale Health and Medical Collection. International Medical News Group. Clinical Psychiatry News. 39.7 (July 2011): p32

7. Natalie, Mc. Giil. 2015. Grafis informasi membantu siswa berhenti merokok. Gale Health and Medical Collection. dengan intensi berhenti merokok dan tidak ada pengaruh norma subyektif dengan intensi berhenti merokok mahasiswa STITEKNAS $\begin{array}{lll}\text { Jambi tahun } & 2015 .\end{array}$ tersebut dalam rangka mendukung program pemerintah. Dan juga sebaiknya memperbanyak lagi gambar-gambar peringatan bahaya merokok di lingkungan kampus

International Medical News Group. The Nation's Health. 45.1 (Feb. 2015): p5

8. Notoatmodjo. 2010. Ilmu Perilaku Kesehatan. Jakarta. Rineka Cipta

9. Wahyuni. 2006. Hubungan Antara Sikap Terhadap Label Peringatan Bahaya Merokok Dengan Intensi Berhenti Merokok Pada Mahasiswa Fakultas Teknik Industri Universitas Ahmad Dahlan. Skripsi. Fakultas Psikologi Universitas Ahmad Dahlan. Yogyakarta

10. WHO. 2008. MPOWER: Six policies to reverse the tobacco epidemic. WHO Report On The Global Tobacco Epidemic, 2008

11. Permatasari. 2013. Pengaruh Sikap, Norma Subjektif, Dan Kontrol Perilaku Terhadap Intensi Berhenti Merokok sebagai Dampak Peraturan Gambar Peringatan Merokok Pada Mahasiswa Strata 1 di Kota Malang. Skripsi. Universitas Brawijaya. Priyoto. 2014. Teori Sikap Dan Perilaku Dalam Kesehatan. Yogyakarta. Nuha Medika 